Please quote as: Troll, J.; Blohm, I. \& Leimeister, J. M. (2016): Revealing the Impact of the Crowdsourcing Experience on the Engagement Process. In: International Conference on Information Systems (ICIS). Dublin, Ireland. 


\title{
Revealing the Impact of the Crowdsourcing Experience on the Engagement Process
}

\author{
Research-in-Progress
}

\author{
Julia Troll1 \\ julia.troll@unisg.ch
}

\author{
Ivo Blohm \\ ivo.blohm@unisg.ch
}

\author{
Jan Marco Leimeister ${ }^{1,2}$ \\ janmarco.leimeister@unisg.ch \\ ${ }^{1}$ University of St. Gallen \\ Institute of Information Management \\ Unterer Graben 21, CH-900o St. Gallen, Switzerland \\ ${ }^{2}$ University of Kassel \\ Research Center for ISDesign (ITeG) \\ Pfannkuchstr. 1, D-34121 Kassel, Germany
}

\begin{abstract}
A largely neglected aspect in crowdsourcing research is the "Crowdsourcing Experience", which every crowdsourcee is necessarily exposed to throughout the ITmediated crowdsourcing journey, potentially stimulating engagement. In the context of value co-creation participant's engagement, defined as a psychological state that fosters directly and indirectly related value contributions, is argued to be a holistic measure for crowdsourcing success. Hence, this paper proposes a theoretical framework of the crowdsourcees' engagement process and a novel approach for assessment. The recommended research design combines case study research with the sequential incident laddering technique to unravel an individual's Crowdsourcing Experience and its impact on engagement. To the knowledge of the authors, the engagement process was not assessed in the field of crowdsourcing yet and no particular research approach exists. This research in progress offers IS-researchers and practitioners initial insights on IT-enabled engagement processes between individuals and entities to enhance knowledge on mutual value-creation.
\end{abstract}

Keywords: Crowdsourcing, Crowdsourcing Experience, Crowdsourcing Journey, Engagement Process, Sequential Incident Laddering Technique

\section{Introduction}

Crowdsourcing, coined after Howe (2006), is an emerging global trend, which 85 percent of the top hundred global brands try to take advantage of (Owyang 2015). It broadly defines a participative, ITmediated activity in which a given entity proposes a task to a crowd to create mutual benefit (Blohm et al. 2013). While there are several functions of crowdsourcing, such as design and innovation, software development and testing, marketing, or any form of support activities (Vuković 2009), it seems as if crowdsourcers' primary attention is currently paid to managing contributions rather than the crowd, its needs and desires. This is also reflected by research in the field of crowdsourcing, which is dominated by studies assessing the absorption of knowledge (Blohm et al. 2013), the efficient and effective management of crowdsourcing processes (Geiger et al. 2011; Stol and Fitzgerald 2014; Vuković 2009), or the evaluation 
of contributions and its value (Afuah and Tucci 2012; Poetz and Schreier 2012), mostly from a crowdsourcer's perspective. However, looking at successful crowdsourcing initiatives, as My Starbucks Idea, Haribo Goldbären Fan-edition, or the SBB Mobile Preview Community, in terms of its huge crowds and intense participation, it can be assumed that value is not only created by resource absorption.

The meaning of value and the process of value creation are rapidly shifting from a product- and firmcentric view to an experience-based view (Prahalad and Ramaswamy 2004). This can be transferred to cocreation activities itself, in which experiences are created, too. Hence, this paper argues that a largely neglected aspect in crowdsourcing research is the "Crowdsourcing Experience" itself, which every crowdsourcee is necessarily exposed to throughout the IT-mediated crowdsourcing journey. This disregard may come with a price. On the one hand, initiators not only risk to loose valuable contributors during or after the interaction due to perceived negative experiences, but also their reputation. A famous example is given by "Pril's crowdsourcing flop", in which an undesirable experience by Henkel caused a public PR-disaster on several virtual channels (Gassmann et al. 2013). On the other hand, initiators miss a promising opportunity to generate crowdsourcees a unique experience, thereby stimulating high quality input and crowdsourcees' overall engagement with the organization. This can create additional value, e.g. in form of positive word of mouth, attracting more contributors and enhanced brand value.

First authors recognized the need for a more experienced-based perspective on crowdsourcing to understand the associated concept of engagement and called for research on that topic (Füller et al. 2009; Pedersen et al. 2013; Vuković 2009). Initial studies reveal insights regarding the experience perception (Djelassi and Decoopman 2013; Riedl et al. 2013), its impact on commitment (Schulten and Schaefer 2015) and early and sustained participation (De Vreede et al. 2013; Nguyen et al. 2015; Sun et al. 2012). However, none of those studies take a process perspective on crowdsourcing to systematically assess the end-to-end crowdsourcee's experience. Yet, this is necessary to understand how and why crowdsourcees engage, from a cognitive, emotional and behavioral perspective, throughout their whole IT-mediated crowdsourcing journey. By looking at only causal relationships between unidimensional definitions of engagement and individual factors, the underlying mechanisms and its ensuing total business value cannot be revealed. To fill this gap, this research in progress proposes a theoretical framework of the crowdsourcees' engagement process and proposes a research design that combines the case study approach with the sequential incident laddering technique, to answer the following question: How does the Crowdsourcing Experience impact the engagement process throughout the crowdsourcing journey?

To the knowledge of the authors the engagement process was not assessed in the field of crowdsourcing, and no particular research approach for assessing IT-enabled, experience-driving stimuli throughout the crowdsourcee's journey exists. The paper is structured as follows: (1) An overview of the research fields of crowdsourcing and customer engagement are provided and relevant concepts derived. (2) The engagement concept and process is applied to the case of crowdsourcing and assumptions are developed. (3) A research design for exploring assumptions and deriving propositions is provided and (4) theoretical as well as practical contributions are presented in detail.

\section{Conceptual and Theoretical Background}

\section{Crowdsourcing}

The fundamental idea of crowdsourcing is that a crowdsourcer (i.e., a company, an institution or a nonprofit organization) proposes to an undefined group of contributors (i.e., individuals, formal or informal teams, other companies), henceforth called crowdsourcees, the voluntary undertaking of a task presented in an open call (Blohm et al. 2013). The ensuing interaction process unfolds over IT-based crowdsourcing platforms (Blohm et al. 2016). Therefore, crowdsourcers can set up their own platform and directly interact with crowdsourcees (e.g., My Starbucks Idea). Alternatively they can refer to intermediaries, such as Innocentive or Testbirds that provide a technical infrastructure and a crowd to which crowdsourcers can propose tasks. Frequently, intermediaries also offer additional services such as task-specification, crowd-acquisition, and aggregation or evaluation of results (Zogaj et al. 2014).

Furthermore, crowdsourcing refers to a participative process in which the crowdsourcer and the crowdsourcees engage to create mutual benefit (Estellés-Arolas and González-Ladrón-De-Guevara 2012). Thus, in a broader context, it relates to the macro-construct of value co-creation (Storbacka et al. 2016). 
In "sponsored co-creation" organizations open themselves to the co-creation efforts of external individuals, including present or potential consumers (Zwass 2010). Thus, the role of crowdsourcees can be manifold. On the one hand, they take the role of a platform-mediated worker and community member, providing solutions for task accomplishment. On the other hand, they are still human beings with prospective needs and desires, who inevitably develop an attitude towards the crowdsourcer, possibly resulting in consumption or referral activities. Hence, in this research paper, crowdsourcees are also viewed as potential or actual consumers and influencers for the crowdsourcer (Leimeister 2009).

In this regard, crowdsourcing success and its business value is assumed to be multidimensional, consisting of directly and indirectly related value contributions (Blohm et al. 2013). First, it may involve contributions, solving a crowdsourcer's problem that cannot be satisfactorily solved in-house (Blohm et al. 2016). However, due to the diverse role of crowdsourcees, benefits may go beyond problem solving as initiators' intention to crowdsource was found to be not only related to likely cost reductions and access to external talent, but also to enhanced brand visibility (Ye and Kankanhalli 2015). Similarly, for crowdsourcees the benefit of participation may be twofold. It can be of economic nature (i.e., a reward or remuneration) or other needs are satisfied, like social recognition, self-esteem, skill development or entertainment, perceived throughout the interaction process (Estellés-Arolas and González-Ladrón-DeGuevara 2012). Thus, value can be produced by outcomes (i.e. instrumental value) and preceding processes (i.e. experiential value). Accordingly, this paper argues that value goes beyond simple transactions and crowdsourcing success needs to be assessed more holistically.

In this context, Storbacka et al. (2016) illustrate that actor engagement is the microfoundation of value cocreation. Without actor engagement, no resource integration can occur and consequently no value can be co-created. Moreover, actor engagement, defined as the activity of engaging in an interactive process, is observable and empirically testable (Storbacka et al. 2016). It is argued that the conceptual and physical context determines why, when and how actors engage. Hence, engagement is inseparably linked to the overall perceived co-creation experience of an actor. Some authors have emphasized the need for researching crowdsourcing from an experience-based perspective (Füller et al. 2009; Pedersen et al. 2013; Vuković 2009) as well as studying the processes and mechanisms that lead to mutual benefits (Zwass 2010). First articles reveal initial insights. De Vreede et al. (2013) proposed a model explaining initial crowdsourcing user engagement, defined as the crowd's quality of effort devoted to open collaboration, suggesting personal interest, goal clarity, and motivation as antecedents. Sun et al. (2012) studied the drivers of sustained participation in micro-task oriented crowdsourcing and found that task-complexity and self-efficacy influences sustained participation. Following on that, a participant engagement index for crowdsourcing was proposed, based on the characteristics of contributions concerning the task (Nguyen et al. 2015). Riedl et al. (2013) exhibit that design choices may positively influence the crowdsourcee's attitude towards the crowdsourcing platform. Process satisfaction and sense of virtual community was found to positively impact affective commitment in crowdsourcing projects due to the results of an experiment (Schulten and Schaefer 2015). Lastly, a case study found that crowdsourcing participation is perceived as a hedonic experience, enhancing brand image (Djelassi and Decoopman 2013).

While obviously interest grows, none of those studies is capable of explaining the underlying mechanisms that drive engagement throughout the virtual interaction process. By looking at only causal relationships between unidimensional definitions of engagement and individual variables, like goal clarity, task complexity, or design, the final engagement outcome and ensuing business value cannot be explained. This is assumed to result from a more complex interplay of experience-driving stimuli and their intermediate, subconscious evaluation by crowdsourcees. Additionally, existing studies either observe attitudinal or behavioral outcomes, but miss to study the interrelatedness of those variables. To explain and influence desired behaviors, psychological states need to be understood. Moreover, engagement behavior is only defined by the amount and characteristic of direct contributions to the task. Due to the diverse role of crowdsourcees and intentions of crowdsourcers, other behavioral responses need to be investigated that generate value (e.g., referral, word of mouth, willingness to return). Lastly, each of those studies focus only on the participation phase of crowdsourcing. While this seems reasonable on the first view, from customer experience research we know that influential experiences may also occur before and after participation (Meyer and Schwager 2007). Therefore, this study suggests to take a process perspective on crowdsourcing by systematically assessing input, process and output factors along the endto-end crowdsourcees' experience to understand how and why crowdsourcees engage. This implies that several types of data need to be considered and triangulated. 
Impact of the Crowdsourcing Experience on Engagement

\section{The Concept of Engagement}

Due to the interdisciplinary character of crowdsourcing and the multiple roles of crowdsourcees (i.e., platform-mediated workers, technology users, community members, and potential or actual consumers and influencers) several perspectives of engagement seem suitable. Relevant definitions are discussed and the most advanced conceptualization of the engagement process is selected as a starting point for closer examination and adaptation for the case of crowdsourcing.

First, from an IS-perspective, user engagement is defined as a situational or enduring emotional, cognitive and behavioral connection between a user and a (technological) resource (Attfield et al. 2011), based on a user experience that extends beyond pure usability ( $\mathrm{O}^{\prime}$ Brien and Toms 2008). A vague description of the user engagement process is offered, consisting of a point of engagement, a period of sustained engagement, disengagement, and (possibly) reengagement (O'Brien and Toms 2008). Behavioral responses (e.g., technology use, length, return) can be observed through interaction patterns (Attfield et al. 2011). Second, employee or work engagement commonly refers to a psychological state that is above and beyond simple satisfaction, as well as a behavioral response that includes e.g., innovative behaviors, proactive contribution, and over-fulfillment of task (Macey and Schneider 2008). Third, community engagement refers to the identification and intrinsically, motivated interaction of community members within the group (Algesheimer et al. 2005). Brodie et al. (2013) identified learning, sharing, advocating, socializing and co-developing as relevant sub-processes. Lastly, the concept of consumer or customer engagement is defined as a psychological state that occurs by virtue of interactive, co-creative customer experiences with a focal agent (Brodie et al. 2011), usually followed by behavioral responses in form of referral, word of mouth, knowledge contributions, or consumption (Kumar et al. 2010; Van Doorn et al. 2010). Customer experience is related to the internal, subjective perception of interactions throughout the customer journey (Johnston and Kong 2011).

Although those definitions differ in terms of the engagement object (i.e., resource/technology, employer, community, or a company) and resulting behavior (i.e., use, contribute, interact, consume) the underlying understanding of engagement is very similar. It can be summarized as a state that develops through a dynamic, iterative process that co-creates value between an engagement subject and an engagement object. This psychological state encompasses various combinations of cognitive, emotional, and behavioral dimensions. The cognitive dimension can be interpreted as a more passive state of immersion and absorption (e.g., being focused and stimulated) (Hollebeek 2011; Hollebeek et al. 2014) or a more active state of cognitive processing to expedite comprehension (e.g., reasoning, learning or decision making) (Mollen and Wilson 2010). The emotional dimension relates to the feelings, activated by an experience (e.g., excitement, boredom, or love). Behavioral responses are referred to as engagement behavior and relate to any direct and indirect value-contribution towards the engagement object. The sum of those behavioral manifestations reflect the total value created by this interaction (Kumar et al. 2010). As an engagement state occurs within co-creative experiences, active participation in the creation of the core-offering is widely assumed as a central antecedent (Brodie et al. 2011; Van Doorn et al. 2010; Vivek et al. 2012). In the customer engagement literature, the most detailed conceptualization of the engagement process was found. As the engagement definitions are analogous, the underlying logic of the psychological process is assumed to be similar. Hence, we take a closer look at this process first and adapt the model with the knowledge derived from the other research fields to the case of crowdsourcing.

\section{The Engagement Process}

Both existing conceptualizations of the engagement process, here from a customer perspective, start with the feeling of satisfaction with the interaction as a preliminary state (Bowden 2009; Sashi 2012). Alone, it may not result in repeat consumption or referral behavior as expectations are only confirmed according to the expectation-disconfirmation theory (Oliver 1977). If one repeats a satisfying interaction e.g., due to perceived attribute-based utility, missing alternatives or switching costs, calculative commitment may develop between the engagement subject and object (Bowden 2009). Commitment is associated with a specific attitudinal position, while calculative relates to rational reasoning (Bowden 2009).

Yet, those rational bonds may be dissolved easily and are of limited value for a company due to the low probability of word of mouth or referral (Sashi 2012). Unless, an enduring feeling of involvement or trust develops, due to increased familiarity, knowledge, and precise expectations towards the engagement 
object (Bowden 2009). While involvement is described as a feeling of personal relevance and importance (Oliva et al. 1995), trust is the assumption that a focal agent is able to respond to someone's needs and has one's best interest at heart (Delgado-Ballester and Luis Munuera-Alemán 2001). Both increase the probability of retention, discount of negative experiences, and the development of affective commitment (Bowden 2009). Affective commitment is an emotional state that expresses a customer's psychological closeness to a focal agent and is positively related to referral and word of mouth (Bowden 2009; Sashi 2012). It is expressed as a holistic or aggregate judgment of an engagement object, independently from its functional attributes.

Nevertheless, a delightful incident may lead to affective commitment right away, even if the engagement subject is less familiar with the engagement object and relies on a more attribute-based evaluation due to imprecise expectations (Bowden 2009; Sashi 2012). Delight is defined as a combination of pleasure, joy and elation as well as unexpected levels of arousal or surprise (Rust and Oliver 2000). Also, intense direct interaction and dialogue is assumed to increase delight (Mascarenhas et al. 2004). When both forms of commitment develop, engagement subject and object are in an enduring relational exchange with strong emotional bonds (Sashi 2012).

Hence, it can be concluded that familiarity of an engagement subject with an engagement object is an input factor in the process of engagement, while the cognitive and emotional evaluation constitute the psychological process, eventually leading to a state of calculative and/or affective commitment and behavioral responses as process outcomes. Presuming a feeling of satisfaction, it is supposed that a sense of delight, involvement, and trust operate as drivers of engagement in a customer-company interaction. Delight operates already in the short term and is therefore effective for unexperienced engagement subjects, while trust needs to develop over a number of satisfying interactions.

\section{Towards an Engagement Theory of the Crowdsourcing Experience}

\section{Crowdsourcing Experience as a Result of the Crowdsourcing Journey}

Independent of the crowdsourcer's original intention, we argue that performing a crowdsourcing initiative creates an experience that may or may not foster engagement through the process of co-creation. The "Crowdsourcing Experience" in this research is defined as a crowdsourcee's internal and subjective perception of the end-to-end IT-mediated crowdsourcing journey, consisting of a series of stimuli, and resulting in a psychological state. It is mainly an online experience, driven by several interaction points (stimuli) over one or more virtual channels. Figure 1 illustrates the crowdsourcing journey developed in analogy to the consumption process, a widely known framework in marketing research that elaborates on the different phases a consumer undergoes before, during and after a buying activity (Oliver 2014). The crowdsourcing journey is a simplified illustration of the four phases, which a crowdsourcee goes through: (1) Starting with the awareness phase, in which the initiative is discovered via some channel; (2) going on with the consideration phase, in which more about it is learned and a decision to continue is made; (3) when eventually the participation phase is entered, in which the task is approached; (4) and lastly, the closing phase, in which e.g., compensation takes place. The journey can be interrupted at any stage. With repeated interaction, the crowdsourcee reiterates the process.

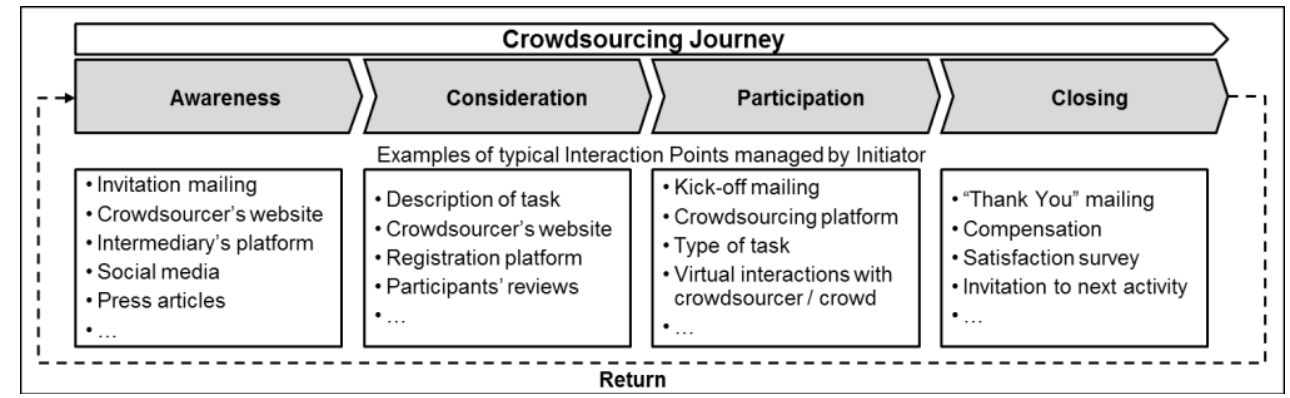

Figure 1. Crowdsourcing Journey

The framework serves to systematically identify and cluster all stimuli that possibly can be perceived by the crowd and that impact their impressions and behaviors. This relates to the "temporal bracketing 
Impact of the Crowdsourcing Experience on Engagement

strategy", suggested by Langley (1999). Because mutual influences are difficult to capture, it is recommended to analyze processes in a sequential fashion by temporarily bracketing one of them into phases or periods. This enables the examination of actions in one phase and its effect on another action in a subsequent phase. With this strategy a large amount of process data can be transformed into related blocks. Hence, the impact of provided stimuli in the journey on psychological processes can be studied.

\section{An Engagement Process for Crowdsourcing}

Henceforth, engagement is conceptualized as a psychological process that models the underlying mechanisms by which a subject develops calculative and affective commitment based on perceived stimuli, resulting in value-contributions for the crowdsourcer.

The literature suggests that one central antecedent of engagement is participation through integration activities. Due to its participative character, it is expected that crowdsourcing has the potential to generate high levels of engagement among crowdsourcees towards the crowdsourcer. It enables the virtual interaction between an individual with an organization and central to the activity is a concrete task, often related to the organization's offerings and strategic direction. The crowdsourcee is the engagement subject, who is approached by a crowdsourcer with the goal to contribute to a task via an online platform. The engagement object can be manifold, depending on the crowdsourcer and the specific set up of the crowdsourcing initiative. Crowdsourcees may engage with inanimate objects like a product or service (e.g. as part of the task), the crowdsourcing organization, or an intermediary (if existent). Besides, crowdsourcees may engage through two-way interactions with other crowdsourcees or representatives. Furthermore, the literature suggests that it must be differentiated between subjects that are new to an engagement object and those that have already established knowledge structures and clear expectations, when assessing their engagement process (Sashi 2012). Crowdsourcees can have varying degrees of familiarity regarding the different potential engagement objects. For instance, this may include prior experiences with the crowdsourcer (e.g., as a customer) or the intermediary (e.g., as a crowdsourcee). Familiarity with the engagement object is supposed to influence the Crowdsourcing Experience and formation of engagement.

Moreover, from the crowdsourcee's perspective, the unfolding IT-mediated crowdsourcing journey comprises a set of diverse stimuli, potentially addressing both, the cognitive and emotional experience dimension. Addressed dimensions regarding each perceived stimuli are evaluated by the crowdsourcee, referred to as experience evaluation, and an intermediate state is generated that may change from stimuli to stimuli, happening mostly unconsciously. Presuming satisfaction, the literature on customer engagement considers delight, involvement, and trust as intermediate states that drive engagement. Delight, also referred to as positive affect, is generally defined as a feeling of unexpected pleasure, joy and surprise. In an IS context, this relates to systems' characteristics as novelty, variety, aesthetics in form of an affective or sensory appeal, and fun (Attfield et al. 2011; O'Brien and Toms 2008). In crowdsourcing, this may refer to an attractive and fun-providing crowdsourcing platform or an appealing object, which is in the center of the task (e.g., an application or website). In the work context, it is also described as enthusiasm and happiness about a job or task (Macey and Schneider 2008). An innovative, novel type of crowdsourcing task may be a reason for perceived delight. However, delight may also be generated in the pre- and post-participation phase (Puccinelli et al. 2009), e.g. due to a more personal and direct interaction between crowdsourcees and crowdsourcer (Mascarenhas et al. 2004).

Involvement generally relates to perceived importance and personal relevance. While in IS, system quality is assumed to be a driver of user involvement (Barki and Hartwick 1989), job or task involvement is understood as a form of true identity of oneself with the work performed (Macey and Schneider 2008). Likewise, in a community context, it refers to the identification with a group due to shared identity (Algesheimer et al. 2005). Lastly, in the consumption context, involvement relates to the personal relevance of a product or service (Puccinelli et al. 2009). Hence, in crowdsourcing, the quality of the crowdsourcing platform and related processes, a good task-person fit, interactions among members, or recognized goals, norms, and rituals may relate to involvement. Additionally, enhanced involvement may be found among crowdsourcees that generally belong to the crowdsourcer's target group or actual consumer pool.

Trust is generally defined as an individual's faith in a given object or subject. In IS, it relates to the user's trust in a specific resource or provider (Attfield et al. 2011), while in a work context it is about trusting 
that an employee's investment will be rewarded in some meaningful way, based upon the norm of reciprocity (Macey and Schneider 2008). From a consumption context, we know that familiarity with a focal agent increases trust. Hence, in crowdsourcing, familiarity with, and a positive reputation of the crowdsourcer, as well as process transparency, perceived fairness and speed concerning compensation may be related to trust.

Next to these another driver is expected to operate in the case of crowdsourcing: empowerment. Ulrich (1989) argues that consumer empowerment leads to stronger customer commitment, if additional information about the company can be gained and response is volitional, irreversible, and public, as it is the case in crowdsourcing. Empowerment positively effects demand, word of mouth, and enjoyment, due to a stronger sense of psychological ownership (Fuchs et al. 2010). From the work context, empowerment relates to a sense of control, impact, meaning and self-efficacy (Spreitzer 1995). Hence, an open or more explorative type of task (i.e., broad but clearly defined scope), relevant topic, skill-task fit, and positive feedback concerning the contribution from the crowdsourcer may cause a sense of empowerment. It needs to be assessed, what, when and how those intermediate states develop throughout the journey.

Subsequently, out of the intermediate states an overall engagement state arises. If satisfaction is achieved throughout the journey and crowdsourcees perceive utility of participation, a form of calculative commitment may be reached. If additionally to satisfaction, a sense of delight, involvement, trust, and/or empowerment arises throughout the journey, affective commitment may be developed. Depending on the type of commitment, different types of engagement behavior towards the engagement objects are assumed. Direct and indirect behavioral value contributions towards the crowdsourcer may refer to repeat participation, virtual or direct word of mouth, referral behavior, further voluntary knowledge contributions (exceeding the original task-scope), and consumption activities (buying/using something from the crowdsourcer) (Nambisan and Nambisan 2008). Calculative commitment is mostly related to repeat participation and affective commitment additionally to the more indirect forms of value contributions. The crowdsourcing engagement process is illustrated in Figure 2.

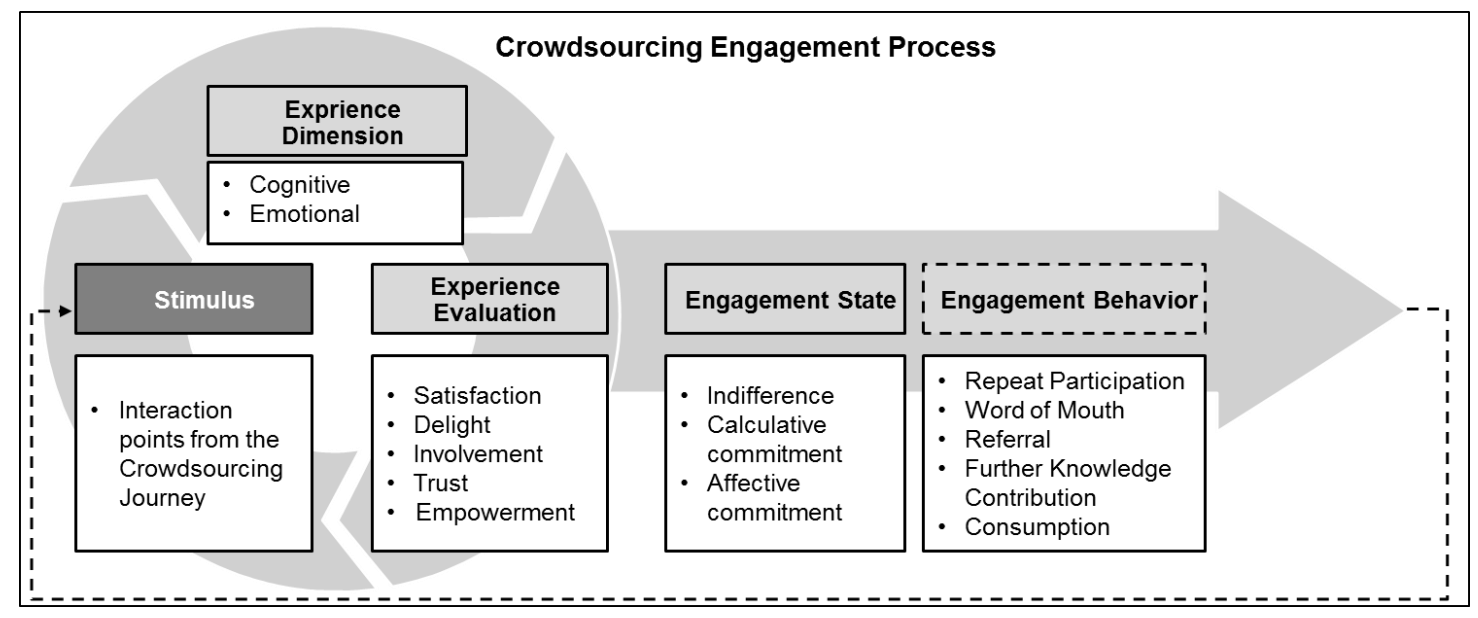

Figure 2. Crowdsourcing Engagement Process

While the crowdsourcing journey is described as a linear process, mechanisms operating in the underlying engagement process may occur at any point of the journey. The objective of the study is to find out, which drivers operate in what part of the journey, resulting in engagement. Nevertheless, mental processes are assumed to have a hierarchical structure in itself. Based on the theoretical framework, several assumptions can be made: (1) The Crowdsourcing Experience impacts the engagement process and resulting behavior. (2) Crowdsourcees' engagement can be directed to different engagement objects. (3) Crowdsourcees' engagement process is dependent on familiarity with the engagement object. (4) Cognitive and emotional perceptions can be activated throughout the interaction process, generating different types of commitment and behavioral responses, depending on the intermediate perceptions of satisfaction, delight, involvement, trust, and empowerment, individually or collectively. By assessing the engagement process in the context of the crowdsourcing journey, those assumptions can be explored and elaborated, by identifying more and less successful patterns of mechanisms and related stimuli. 
Impact of the Crowdsourcing Experience on Engagement

\section{Recommended Research Design}

\section{Case Study Research: Investigating Different Crowdsourcing Journeys}

Each crowdsourcing initiative can offer crowdsourcees a unique IT-mediated interaction process, consisting of many consecutive and somehow interrelated experience-driving stimuli. Thus, experimental control and manipulation is hard to realize. The state of knowledge concerning the engagement process is still low, while complexity of the research phenomenon is high. Furthermore, different data sources, providing information about stimuli, perceived experiences, and behavioral responses need to be triangulated. Hence, as this research wants to find out "how" and "why" crowdsourcees engage throughout the IT-mediated interaction process, a case study approach for illustration and advancement of the conceptualized engagement process seems suitable (Yin 2013). The goal is to extend knowledge on engagement by identifying the mechanism, its interrelatedness (patterns) and associated stimuli characteristics. This refers to an approach by Lee et al. (1999), called "theory elaboration", in which researchers frame the research within the context of the existing body of knowledge and induce the processes by which variables unfold. A natural setting ensures that findings can be generalized to actual processes. In contrast to quantitative research, in case study research, the generalization of results is not based on principles of statistical interference (Yin 2013). The theoretical framework serves as a basis for analyzing empirical findings to ensure "analytic generalization" (Yin 2013). Moreover, a so called "holistic, multiple-case" design is chosen (Yin 2013). Multiple case studies with a single unit of analysis ("holistic") allow researchers to verify findings within and across cases and improve internal and external validity (Yin 2013). Additionally, assessing different cases increases the chance to discover more experience patterns that lead to engagement, which would remain undiscovered by looking at only one case.

As recommended by Yin (2013) for the replication of findings, the research opts for investigating three typical and comparable crowdsourcing cases from Swiss Companies with slightly differently designed crowdsourcing journeys. Cases were selected based on similar task-design and crowd-characteristics (i.e., familiarity with engagement objects, cultural background and income level), but different stimuli characteristics. Three crowdsourcing projects could be identified, in which a relatively homogeneous enduser crowd is asked to test a mobile application (i.e., functionalities, design, and usability) and to propose ideas on a crowdsourcing platform. Stimuli characteristics are slightly differently designed e.g., in terms of platform design, campaign duration, compensation, use of intermediary, and amount of interactions with the crowd. Hence, different experiences are created and can be evaluated.

\section{Data Collection and Analysis}

To ensure construct validity, multiple sources of evidence are chosen (Yin 2013), including (1) interviews with crowdsourcing initiators, (2) interviews with crowdsourcees, and (3) crowdsourcing platform data.

First, to understand the initiative's intended Crowdsourcing Experience, semi-structured interviews with initiators are conducted. Based on that, planned crowdsourcing journeys with all its potential stimuli are visualized. Additionally, a focus group interview with all crowdsourcers is conducted, in which the engagement process model is presented and potential drivers for each crowdsourcing journey discussed.

Secondly, seven to ten in-depth interviews with crowdsourcees of each case are conducted by using an interview approach called "Sequential Incident Laddering Technique" (SILT) (Jüttner et al. 2013). This approach integrates two well-established interview techniques: laddering (Reynolds and Gutman 1988) and the sequential incident technique (SIT) (Stauss and Weinlich 1997). The SIT is a process-oriented, qualitative interviewing technique, which facilitates the collection of "incidents" (i.e., experience driving stimuli). Laddering is a technique where a seemingly simple response to a question is pushed by the interviewer to identify subconscious psychological processes. Respondents are first asked to recall sequentially all stimuli from the crowdsourcing journey. Next, the interviewer asks questions on how each stimuli was perceived to establish the link between the stimulus and crowdsourcee's (a) cognitive and emotional perceptions, (b) experience evaluation (i.e., intermediate state), (c) and behavioral response. Lastly, crowdsourcee's final engagement state (i.e., commitment) and (planned) engagement behavior towards an engagement object is captured. The state is evaluated by asking interviewees to describe their attitude, as commitment is also described as an attitudinal judgment. To avoid a recall bias (Koenig-Lewis and Palmer 2008) crowdsourcees are interviewed shortly after participation. 
Thirdly, inspired by the user and work- engagement-perspective, behavioral platform data is assessed, concerning (a) the crowdsourcees' time spent on the platform and with the test object, (b) the length (word count), and (c) level of detail of contributions (i.e. under-/ over-fulfillment of task), to verify behavioral responses. Additionally, data about demographic information and prior experiences is collected from the platform. Figure 3 illustrates the SILT-approach and serves, together with the visualized crowdsourcing journey, as a structural guidance for the interview.

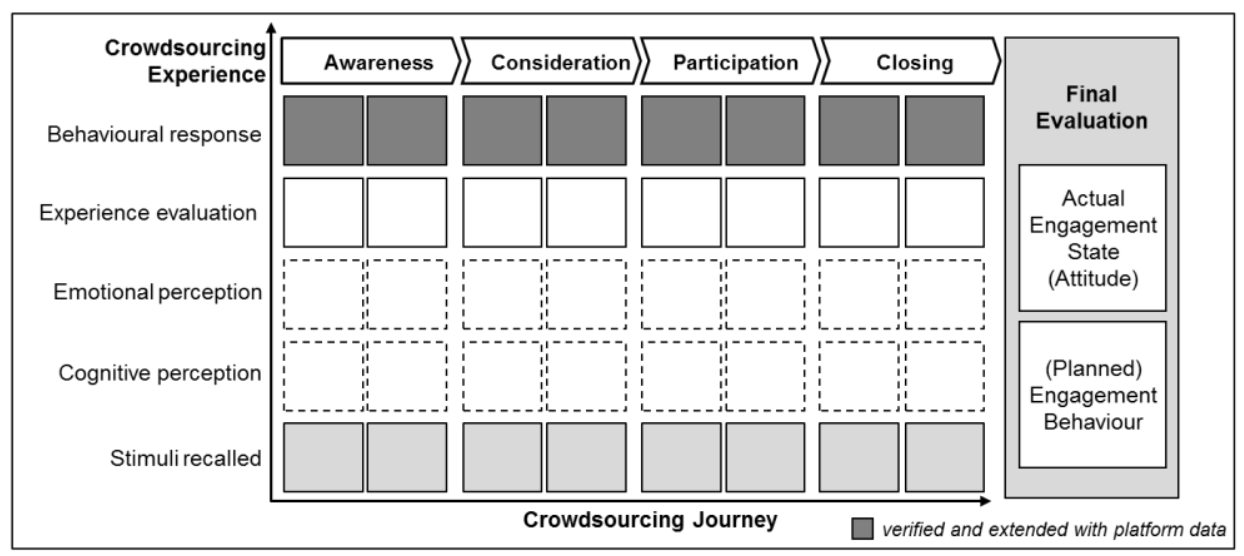

Figure 3. Interview-Approach to Unravel the Crowdsourcing Experience

Data within each case is transcribed and assessed by applying qualitative content analysis. According to Langley (1999) and Tsoukas (1989), a solely inductive or deductive approach for elaboration of a process theory is rarely seen. Instead, closing the gap between data and theory can begin at either or both ends and often iterates between them. We plan to apply an initial category system based on the conceptualized engagement process and assess data according to those categories: experience dimensions (i.e., cognitive, emotional, and behavioral); engagement object towards which named perceptions were directed; experience evaluation concerning a specific stimuli (intermediate state); attitude towards an engagement object; and (planned) engagement behavior. To allow for the identification of new categories and relevant sub-categories, the system will be iteratively adapted throughout the analysis within and across cases. Based on that, patterns of stimuli-related intermediate states and resulting commitment can be assessed.

\section{Conclusion}

Applying the engagement concept and process to the case of crowdsourcing and deploying an adapted form of SILT as a unique measuring approach is a first step in offering IS-researchers an experience-based perspective on crowdsourcing. It proposes a new way of exploring the mutual value creation process of crowdsourcer and crowdsourcees. The integration of those rather new research fields has the advantage that valuable knowledge for both can be derived. Although diverse research about crowdsourcing increased, it is still far from being established and empirical studies are rare (Zhao and Zhu 2014). Generally, crowdsourcing facilitates the connectivity of people, organizations and societies via a technological platform. In the center of this research is the IT-mediated Crowdsourcing Experience, generated through experience-driving stimuli. Hence, the proposed research study contributes to the IS literature, supposed to deliver insights on the so far under-researched concept of IT-enabled engagement processes between individuals and entities, from a psychological and behavioral perspective. It will provide researchers with a crowdsourcing-specific process model, extended by the mechanisms driving engagement, and thus value. Additionally, the concept of engagement is considered as a relatively young perspective in several research fields. By delivering first insights on the engagement process, in the context of value co-creation, the aim is to support the progress of the concept from an emergent theme to a more mature construct. Nevertheless, developing a better understanding of the currently realized Crowdsourcing Experience and the underlying mechanisms of the engagement process may help practitioners to improve the design and management of future crowdsourcing journeys and identify engagement opportunities. 


\section{References}

Afuah, A., and Tucci, C. L. 2012. "Crowdsourcing as a Solution to Distant Search," Academy of Management Review (37:3), pp. 355-375.

Algesheimer, R., Dholakia, U. M., and Herrmann, A. 2005. "The Social Influence of Brand Community: Evidence from European Car Clubs," Journal of marketing (69:3), pp. 19-34.

Attfield, S., Kazai, G., Lalmas, M., and Piwowarski, B. 2011. "Towards a Science of User Engagement (Position Paper)," WSDM Workshop on User Modelling for Web Applications.

Barki, H., and Hartwick, J. 1989. "Rethinking the Concept of User Involvement," MIS quarterly), pp. 53-63.

Blohm, I., Leimeister, J. M., and Krcmar, H. 2013. "Crowdsourcing: How to Benefit from (Too) Many Great Ideas," MIS Quarterly Executive (12:4), pp. 199-211.

Blohm, I., Riedl, C., Füller, J., and Leimeister, J. M. 2016. "Rate or Trade? Identifying Winning Ideas in Open Idea Sourcing," Information Systems Research (27:1), pp. 27-48.

Bowden, J. L.-H. 2009. "The Process of Customer Engagement: A Conceptual Framework," Journal of Marketing Theory and Practice (17:1), pp. 63-74.

Brodie, R. J., Hollebeek, L. D., Juric, B., and Ilic, A. 2011. "Customer Engagement: Conceptual Domain, Fundamental Propositions, and Implications for Research," Journal of Service Research), p. 1094670511411703.

Brodie, R. J., Ilic, A., Juric, B., and Hollebeek, L. 2013. "Consumer Engagement in a Virtual Brand Community: An Exploratory Analysis," Journal of Business Research (66:1), pp. 105-114.

De Vreede, T., Nguyen, C., De Vreede, G.-J., Boughzala, I., Oh, O., and Reiter-Palmon, R. 2013. "A Theoretical Model of User Engagement in Crowdsourcing," in Collaboration and Technology. Springer, pp. 94-109.

Delgado-Ballester, E., and Luis Munuera-Alemán, J. 2001. "Brand Trust in the Context of Consumer Loyalty," European Journal of marketing (35:11/12), pp. 1238-1258.

Djelassi, S., and Decoopman, I. 2013. "Customers' Participation in Product Development through Crowdsourcing: Issues and Implications," Industrial Marketing Management (42:5), pp. 683-692.

Estellés-Arolas, E., and González-Ladrón-De-Guevara, F. 2012. "Towards an Integrated Crowdsourcing Definition," Journal of Information Science (38:2), pp. 189-200.

Fuchs, C., Prandelli, E., and Schreier, M. 2010. "The Psychological Effects of Empowerment Strategies on Consumers' Product Demand," Journal of Marketing (74:1), pp. 65-79.

Füller, J., Mühlbacher, H., Matzler, K., and Jawecki, G. 2009. "Consumer Empowerment through Internet-Based Co-Creation," Journal of Management Information Systems (26:3), pp. 71-102.

Gassmann, O., Winterhalter, S., and Wecht, C. H. 2013. "Crowdsourcing: Tipps, Damit Es Gelingt," IO Management), pp. 44-50.

Geiger, D., Seedorf, S., Schulze, T., Nickerson, R. C., and Schader, M. 2011. "Managing the Crowd: Towards a Taxonomy of Crowdsourcing Processes," AMCIS.

Hollebeek, L. 2011. "Exploring Customer Brand Engagement: Definition and Themes," Journal of strategic Marketing (19:7), pp. 555-573.

Hollebeek, L. D., Glynn, M. S., and Brodie, R. J. 2014. "Consumer Brand Engagement in Social Media: Conceptualization, Scale Development and Validation," Journal of Interactive Marketing (28:2), pp. 149-165.

Howe, J. 2006. "The Rise of Crowdsourcing," Wired magazine (14:6), pp. 1-4.

Johnston, R., and Kong, X. 2011. "The Customer Experience: A Road-Map for Improvement," Managing Service Quality: An International Journal (21:1), pp. 5-24.

Jüttner, U., Schaffner, D., Windler, K., and Maklan, S. 2013. "Customer Service Experiences: Developing and Applying a Sequentialincident Laddering Technique," European Journal of Marketing (47:5/6), pp. 738-769.

Koenig-Lewis, N., and Palmer, A. 2008. "Experiential Values over Time-a Comparison of Measures of Satisfaction and Emotion," Journal of marketing management (24:1-2), pp. 69-85.

Kumar, V., Aksoy, L., Donkers, B., Venkatesan, R., Wiesel, T., and Tillmanns, S. 2010. "Undervalued or Overvalued Customers: Capturing Total Customer Engagement Value," Journal of Service Research (13:3), pp. 297-310.

Langley, A. 1999. "Strategies for Theorizing from Process Data," Academy of Management review (24:4), pp. 691710.

Lee, T. W., Mitchell, T. R., and Sablynski, C. J. 1999. "Qualitative Research in Organizational and Vocational Psychology, 1979-1999," Journal of vocational behavior (55:2), pp. 161-187.

Macey, W. H., and Schneider, B. 2008. "The Meaning of Employee Engagement," Industrial and organizational Psychology (1:1), pp. 3-30. 
Mascarenhas, O. A., Kesavan, R., and Bernacchi, M. 2004. "Customer Value-Chain Involvement for Co-Creating Customer Delight," Journal of consumer marketing (21:7), pp. 486-496.

Meyer, C., and Schwager, A. 2007. "Customer Experience," Harvard business review), pp. 1-11.

Mollen, A., and Wilson, H. 2010. "Engagement, Telepresence and Interactivity in Online Consumer Experience: Reconciling Scholastic and Managerial Perspectives," Journal of business research (63:9), pp. 919-925.

Nambisan, S., and Nambisan, P. 2008. "How to Profit from a Better'virtual Customer Environment'," MIT Sloan management review (49:3), p. 53.

Nguyen, C., Tahmasbi, N., de Vreede, T., de Vreede, G.-J., Oh, O., and Reiter-Palmon, R. 2015. "Participant Engagement in Community Crowdsourcing," Paper accepted to be presented at the European Conference of Information Systems, Münster, Germany.

O'Brien, H. L., and Toms, E. G. 2008. "What Is User Engagement? A Conceptual Framework for Defining User Engagement with Technology," Journal of the American Society for Information Science and Technology (59:6), pp. 938-955.

Oliva, T. A., Oliver, R. L., and Bearden, W. O. 1995. "The Relationships among Consumer Satisfaction, Involvement, and Product Performance: A Catastrophe Theory Application," Behavioral Science (40:2), pp. 104-132.

Oliver, R. L. 1977. "Effect of Expectation and Disconfirmation on Postexposure Product Evaluations: An Alternative Interpretation," Journal of applied psychology (62:4), p. 480.

Oliver, R. L. 2014. Satisfaction: A Behavioral Perspective on the Consumer. Routledge.

Owyang, J. 2015. "The State of Crowdsourcing in 2015," Crowd Companies ${ }^{\mathrm{TM}}$, https://en.eyeka.com/resources/analyst-reports\#CSreport2015.

Pedersen, J., Kocsis, D., Tripathi, A., Tarrell, A., Weerakoon, A., Tahmasbi, N., Xiong, J., Deng, W., Oh, O., and De Vreede, G.-J. 2013. "Conceptual Foundations of Crowdsourcing: A Review of Is Research," System Sciences (HICSS), 2013 46th Hawaii International Conference on: IEEE, pp. 579-588.

Poetz, M. K., and Schreier, M. 2012. "The Value of Crowdsourcing: Can Users Really Compete with Professionals in Generating New Product Ideas?," Journal of Product Innovation Management (29:2), pp. 245-256.

Prahalad, C. K., and Ramaswamy, V. 2004. "Co-Creation Experiences: The Next Practice in Value Creation," Journal of interactive marketing (18:3), pp. 5-14.

Puccinelli, N. M., Goodstein, R. C., Grewal, D., Price, R., Raghubir, P., and Stewart, D. 2009. "Customer Experience Management in Retailing: Understanding the Buying Process," Journal of retailing (85:1), pp. 1530.

Reynolds, T. J., and Gutman, J. 1988. "Laddering Theory, Method, Analysis, and Interpretation," Journal of advertising research (28:1), pp. 11-31.

Riedl, C., Blohm, I., Leimeister, J. M., and Krcmar, H. 2013. "The Effect of Rating Scales on Decision Quality and User Attitudes in Online Innovation Communities," International Journal of Electronic Commerce (17:3), pp. 7-36.

Rust, R. T., and Oliver, R. L. 2000. "Should We Delight the Customer?," Journal of the Academy of Marketing Science (28:1), pp. 86-94.

Sashi, C. 2012. "Customer Engagement, Buyer-Seller Relationships, and Social Media," Management decision (50:2), pp. 253-272.

Schulten, M. B., and Schaefer, F. 2015. "Affective Commitment and Customer Loyalty in Crowdsourcing: Antecedents, Interdependencies, and Practical Implications," International Review of Retail, Distribution \& Consumer Research (25:5), pp. 516-528.

Spreitzer, G. M. 1995. "Psychological Empowerment in the Workplace: Dimensions, Measurement, and Validation," Academy of management Journal (38:5), pp. 1442-1465.

Stauss, B., and Weinlich, B. 1997. "Process-Oriented Measurement of Service Quality: Applying the Sequential Incident Technique," European Journal of Marketing (31:1), pp. 33-55.

Stol, K.-J., and Fitzgerald, B. 2014. "Two's Company, Three's a Crowd: A Case Study of Crowdsourcing Software Development," Proceedings of the 36th International Conference on Software Engineering: ACM, pp. 187198.

Storbacka, K., Brodie, R. J., Böhmann, T., Maglio, P. P., and Nenonen, S. 2016. "Actor Engagement as a Microfoundation for Value Co-Creation," Journal of Business Research (69:8), pp. 3008-3017.

Sun, Y., Fang, Y., and Lim, K. H. 2012. "Understanding Sustained Participation in Transactional Virtual Communities," Decision Support Systems (53:1), pp. 12-22.

Tsoukas, H. 1989. "The Validity of Idiographic Research Explanations," Academy of Management Review (14:4), pp. 551-561. 
Ulrich, D. 1989. "Tie the Corporate Knot: Gaining Complete Customer Commitment," MIT Sloan Management Review (30:4), p. 19.

Van Doorn, J., Lemon, K. N., Mittal, V., Nass, S., Pick, D., Pirner, P., and Verhoef, P. C. 2010. "Customer Engagement Behavior: Theoretical Foundations and Research Directions," Journal of Service Research (13:3), pp. 253-266.

Vivek, S. D., Beatty, S. E., and Morgan, R. M. 2012. "Customer Engagement: Exploring Customer Relationships Beyond Purchase," Journal of Marketing Theory and Practice (20:2), pp. 122-146.

Vuković, M. 2009. "Crowdsourcing for Enterprises," Services-I, 2009 World Conference on: IEEE, pp. 686-692.

Ye, H. J., and Kankanhalli, A. 2015. "Investigating the Antecedents of Organizational Task Crowdsourcing," Information \& Management (52:1), pp. 98-110.

Yin, R. K. 2013. Case Study Research: Design and Methods. Sage publications.

Zhao, Y., and Zhu, Q. 2014. "Evaluation on Crowdsourcing Research: Current Status and Future Direction," Information Systems Frontiers (16:3), pp. 417-434.

Zogaj, S., Bretschneider, U., and Leimeister, J. M. 2014. "Managing Crowdsourced Software Testing: A Case Study Based Insight on the Challenges of a Crowdsourcing Intermediary," Journal of Business Economics (84:3), pp. $375-405$.

Zwass, V. 2010. "Co-Creation: Toward a Taxonomy and an Integrated Research Perspective," International Journal of Electronic Commerce (15:1), pp. 11-48. 